\title{
Construindo comunidades seguras: jogo Oasis e as condições de protagonismos e segurança cidadã da comunidade de Itinga- Lauro de Freitas
}

Mirian Souza Fonseca mirian.fonseca97@gmail.com Bahia. Brasil.

\section{RESUMO}

RESUMO

O presente artigo apresenta como o jogo de mobilização social e transformação comunitária criado pelo Instituto Elos, jogo oasis, contribuiu para as condições de segurança cidadã na comunidade de Itinga- Lauro de Freitas, em 2013 durante as ações do Programa Conjunto da ONU - Segurança com Cidadania. Para verificar as condições de segurança cidadã, mobilização e protagonismo comunitário dentro da comunidade, foi utilizado o Indicador Qualitativo de Segurança Cidadã - IQSC, produzido por Joselita Frutuoso Macêdo Filha na sua tese de doutorado pelo programa de Pós-graduação em Planejamento territorial e Desenvolvimento social da Universidade Católica de Salvador(PPGPTDS/UCSAL). Para coleta das evidências foi feita uma pesquisa na hemeroteca produzida pela mesma, utilizando a palavra-chave: Oasis e os resultados foram analisados e organizados neste artigo.
\end{abstract}

PALAVRAS-CHAVE: Itinga. Jogo Oasis. Segurança Cidadã. IQSC. 


\section{INTRODUÇÃO}

Compreender uma comunidade a partir do olhar de dentro dela, nos faz perceber como ela se organiza e busca suas formas de resistência às condições locais de vulnerabilidade e violência. Itinga é um bairro-cidade dentro de Lauro de Freitas, com inúmeras vulnerabilidades no seu seio, mas que acima de tudo, tem uma capacidade enorme para se articular e buscar formas para mudar/melhorar sua realidade de violência, participação e coesão social (HERCOG e MACÊDO FILHA, 2015 apud MACÊDO FILHA, 2018). Local que marca o início da formação social e política de vários adolescentes e jovens que vivem nele.

Itinga, é o local onde nasci, cresci e ouvi a palavra vulnerabilidade social pela primeira vez, em 2012, durante o curso de agentes de comunicação para o desenvolvimento oferecido pela Cipó Comunicação Interativa como parte das ações do programa conjunto da ONU-segurança com Cidadania. O Programa Conjunto teve como objetivo prevenir a violência, criando ambientes mais seguros e saudáveis para meninos e meninas entre 10 e 24 anos. Foi implementado em três municípios brasileiros (Lauro de Freitas-BA; Contagem-MG e Vitória-ES) entre os anos de 2010 e 2013. Seis agências da ONU (UNODC, UNICEF, UNESCO, OIT, ONUHABITAT e PNUD) participaram da iniciativa, desenvolvendo ações diversas nos municípios participantes. (HERCOG, 2016 p. 26). Ao fim do curso alguns jovens foram convidados para participar das reuniões colegiadas do programa. Foi participando das reuniões com olhar de curiosidade que passei a integrar a comissão de comunicação e mobilização social do programa conjunto e estagiar como assistente de comunicação do mérito Juvenil, programa de autodesenvolvimento, que busca reduzir a violência que afeta jovens entre 14 a 25 anos, por meio do cumprimento voluntário de regras, da auto-regulação do comportamento e da promoção de mecanismos de controle social (UNODC, 2019). Em 2013 participei da formação Oasis Training: formação de multiplicadores da metodologia elos e jogo Oasis, realizada pela Organização das Nações Unidas para a Educação, a Ciência e a Cultura- UNESCO, em parceria com o Instituto Elos.

Tal experiência após a finalização do programa conjunto me levou a envolvimentos com coletivos e organizações com foco na garantia de direitos humanos para meninos e meninas e mobilizações artísticos-culturais na comunidade. Itinga era um território conhecido pela violência; logo, a busca por ações que mostrassem o outro lado da comunidade que não estavam sendo noticiado nas mídias, era um dos objetivos dos moradores, lideranças e grupos locais. Joselita Frutuoso de Araújo Macêdo Filha (2018) em sua tese de doutorado pelo Programa de Pós-graduação em Planejamento territorial e Desenvolvimento social da Universidade Católica de Salvador- (PPGPTDS/UCSAL), intitulada, " A Ira fértil: Resiliência na resistência ao medo em Itinga- Lauro de Freitas",. A apresenta observações sobre sua experiência no Programa Conjunto da ONU em Lauro de Freitas- Bahia na comunidade de Itinga. Para Macêdo Filha (2018):

Tal experiência teve a mobilização e o protagonismo comunitários como fundamentais sob o princípio da Convivência e Segurança Cidadã. Para esta demonstração se desenvolveu como suporte de análise um indicador sobre as condições de segurança pública, que considera as especificidades de cada território e as 
Em contato direto com a pesquisa de Macêdo Filha, através de apoio técnico prestado à mesma, consegui compreender quais ações de participação geram resiliência e resistência ao medo dentro da comunidade.

Outra experiência com comunidade surgiu através do grupo de pesquisa Desenvolvimento, Sociedade, e Natureza - DSN/UCSAL, como voluntária de pesquisa. No DSN comecei a acompanhar a comunidade da sub-bacia do riacho Mané Dendê, que integra a bacia hidrográfica do rio do Cobre, e abrange cinco bairros localizados no Subúrbio Ferroviário de Salvador (Itacaranha, Terezinha, Rio Sena, Ilha Amarela e Plataforma). Imersa na realidade da comunidade, alguns questionamentos acerca de como a participação comunitária se organizava entre eles, interessei-me em participar do Guerreiros sem Armas - programa de formação de lideranças, mobilização comunitária e transformação social do Instituto Elos, em julho de 2019. Fez parte da formação, uma imersão na experiência da comunidade do Morro do Cruzeiro- Santos/SP com a filosofia do Elos e retomada da aplicação do jogo oasis. Desde então venho pesquisando como a sua aplicação na comunidade pode fortalecer o protagonismo comunitário. No estudo apresentado não iremos nos aprofundar sobre a comunidade da sub-bacia do riacho Mané Dendê, iremos compreender quais foram os impactos da aplicação do jogo na comunidade de Itinga durante o programa conjunto da ONU, na tentativa de possivelmente realizar a experiência na comunidade Mané Dendê.

Na tese de Macêdo Filha (2018), o uso do jogo Oasis é reconhecido como instrumento de mobilização para o protagonismo comunitário, mas essa condição não é examinada em particularidade. Isto nos levou ao questionamento sobre que indícios de potenciais protagonismos comunitários nesse jogo, considerando a territorialidade, as evidências de segurança cidadã elencadas na tese apontam? Neste artigo pretende-se responder a este questionamento apropriando-se da metodologia daquela tese.

\section{JOGO OASIS, PROTAGONISMO COMUNITÁRIO E SEGURANÇA CIDADÃ NA COMUNIDADE DE ITINGA- LAURO DE FREITAS}

O município Lauro de Freitas, integra a região metropolitana de SalvadorBahia. De acordo com Flexor e Alencar (2012) era tida como cidade rural até a década de 1970 e margeada pelo rio Ipitanga, que marca a história do município e caminha em direção ao mar, criando infraestrutura e mercado imobiliário direcionados a uma população de classe média e média alta, enquanto na outra margem do rio, cresce uma população predominante de classe média baixa e baixa. Atualmente a cidade tem área total de $57.662 \mathrm{~km} 2$, tendo população estimada de 198.440 pessoas, até o ano de 2013 estava dividida em 9 bairros e em 2014, após a redefinição do município, passou a ser composta por 18 bairros, sendo Itinga um dos maiores, em termo de população.

Itinga nasceu do investimento em loteamentos populares e conjuntos habitacionais. Caracterizada, na década de 60 , como área rural, era constituída principalmente por fazendas, muitas das quais abandonadas, pertencentes a comercial passou ser um espaço interessante para o mercado imobiliário, por 
conta da sua localização, se tratava da primeira área no vetor norte de expansão de Salvador fora dos seus limites territoriais, situada próxima ao final da avenida Paralela; entre a Estrada do Coco (BA-099) e a rodovia CIA-Aeroporto (BA-526) (DIAS, 2006 p. 89).

Na década de 1990, passou por um processo de crescimento acelerado e a sua população foi aumentando velozmente a cada ano (HERCOG, 2016 p. 27). Apresenta área de 381 hectares, e cerca de 73.484 habitantes. . Itinga fez parte da formação inicial de Lauro de Freitas e muitos moradores tradicionais e seus familiares vivem atividades de serviço e da pesca, o que chama atenção por ser atividade rural em área metropolitana, conurbada com Salvador, a capital do Estado da Bahia. O bairro está dividido em 42 loteamentos e é marcado por elevadas taxas de criminalidade de violência urbana (PNUD, 2013 apud HERCOG, 2016 p. 28).

A comunidade enfrenta grandes desafios com questões relacionadas à saúde, educação, infraestrutura etc.. O mais grave problema enfrentado pela mesma está ligado ao tráfico de drogas que atinge diretamente a população mais jovem. Segundo a cartilha do plano integral participativo de convivência e segurança cidadã de Itinga, produzido durante o programa conjunto da ONU- Segurança com Cidadania, muitos adolescentes e jovens vivem em lares desestruturados, com pais alcoólatras com baixa escolaridade, desempregados ou subempregados (PNUD, 2013 p. 20).

Contudo, a comunidade também mantém uma população mobilizada em transformar a realidade local, através da arte, religiosidade, mobilizações sociais e manifestações artísticos-culturais que para Macêdo Filha (2018), pode ser entendida como, assertivas "a respeito das condições de possibilidades das comunidades se apropriarem de certa maneira do território em termos de participação, autonomia, democracia, etc. que pode ser lido como pacífica em relação à segurança" (MACÊDO FILHA, 2018 p. 123).

\subsection{Segurança cidadã}

O conceito de segurança cidadã foi criado pelo Programa das Nações Unidas para o Desenvolvimento- PNUD e trata-se da uma forma específica e restrita da segurança humana com intuito de garantir proteção às pessoas, preservando da violência e de práticas de delito estabelecidos pela cultura de paz. (PNUD, 2013 p.15) É responsável por promover ambientes mais seguros para fortalecimento relações, das pessoas e órgãos públicos, promovendo convivência para diversas resoluções de conflitos. Na segurança cidadã, a violência é compreendida como um fenômeno chamado multicausal, pois como o próprio termo aponta, possui inúmeras causas, desde a violência acidental até o crime organizado (PNUD, 2013 p. 17), logo para estar seguro é importante que o enfrentamento não esteja limitado a ações tradicionais das forças oficiais de segurança, mas sim, que envolva formas plurais de enfrentamento, onde a pessoa seja foco da sua atuação e proteção à vida.

A segurança com cidadania é colocada pela comunidade de Itinga, como ter direito à informação, educação, e segurança pública e está essencialmente relacionados com os direitos humanos, no seu mais amplo aspecto, como direito à 
vida, integridade pessoal, inviolabilidade do domicílio, direito humano à comunicação, liberdade de ir e vir (PNUD, 2013 p. 16).

\subsection{Indicador Qualitativo de Segurança Cidadã - IQSC}

O Indicador Qualitativo de Segurança Cidadã- IQSC desenvolvido por Macêdo Filha (2018), busca observar as condições locais de modo de vida, de violência e de paz, buscando tensões entre cidadania regulada e territorialidade cidadã." A metodologia propõe que sejam identificados os elementos que põem sobre tensão a regulação da segurança ou a territorialidade cidadã, identificando os eventos, que são as evidências empíricas. " (MACÊDO FILHA, 2018 p.56). Para identificação das tensões, é preciso compreender que a segurança é estabelecida de duas formas: uma forma regulada de segurança e outra forma territorial de segurança. Ou seja:

1) O da cidadania regulada manifestada por "eu quero estar seguro(a), porque acredito na regulação que coloca a polícia na rua, que por sua vez reprime o crime e me dá a percepção de que eu esteja seguro(a)"; ou 2) O da territorialidade cidadã manifestada por "eu quero estar seguro porque eu construo uma forma de segurança que é o resultado de uma convivência comum baseada na solidariedade e que é constituinte do território onde vivo". (MACÊDO FILHA, 2018 p. 54)

A mesma, ainda acrescenta que a relação das tensões entre cidadania regulada- territorialidade cidadã apresenta quatro tipos de naturezas de tensões resultantes da gestão territorial do "acontecer solidário" na localidade estudada, quais sejam:

T1 - por manifestações de resiliência - relações de convivência comunitária pautada no acontecer solidário, reforçando a participação e o protagonismo; T2 - por expressão de cidadania e atuação participativa - "domínio" territorial - gestão territorial dividida ou compartimentada com ênfase na participação e ao mesmo tempo na repressão com presença do Estado; T3 - por situação de risco e vulnerabilidade - em relações geradoras de conflitos; e, T4 - por atuação criminosa - confrontos e eventos de violência criminosa. (MACÊDO FILHA, 2018 p.56)

Para validação dos dados é preciso consulta em jornais, revistas ou periódicos que expressem a realidade local da comunidade.

A partir da identificação das naturezas das tensões, identificam-se as determinações que são explicativas da existência dos eventos de violência. As determinações explicam o que acontece na comunidade e na relação com a sociedade, também da cidadania regulada em relação à territorialidade cidadã. Sempre observando o protagonismo cidadão pela resiliência como núcleo desse estudo. A partir daí, retorna-se à análise das evidências estabelecendo variáveis independentes e dependentes. (MACÊDO FILHA, 2018 p.56)

As variáveis dependentes referem-se aos elementos decorrentes das variáveis independentes, que por sua vez, referem-se às determinações apresentadas. Os quadros a seguir foram reproduzidos da tese de Macêdo Filha (2018), a fim de 
demonstrar como se organizam as variáveis independentes- interligadas e as determinações que definem o IQCS.

Quadro 1. Variáveis Independentes do IQCS

\section{VARIÁVEIS INTERDEPENDENTES (e interligadas)}

VI 1- Condição de ser pessoa, de pertencer à espécie humana e estar vivo

VI 2- Dignidade como valor básico dos DDHH

VI 3- Liberdade, igualdade e solidariedade e direitos fundamentais na democracia.

VI 4- Escolha do projeto civilizatório

Elaborado por Macêdo Filha, 2018 p. 59

Quadro 2- Determinações IQSC

\begin{tabular}{|c|c|}
\hline DETERMINAÇÕES & DESCRIÇÃO DA DETERMINAÇÃO \\
\hline $\begin{array}{l}\text { 1.Determinação } \\
\text { sociointeracional (DSI) }\end{array}$ & $\begin{array}{l}\text { Tensiona quando a existência de fatores de risco individuais, domésticos ou sociais } \\
\text { que, a partir de um efeito cumulativo, colocam as pessoas em condições e situações } \\
\text { vulneráveis, aumentando as chances de se tornarem vítima ou agentes de violência } \\
\text { EM contextos históricos, relacionais e locacionais próprios. }\end{array}$ \\
\hline $\begin{array}{l}\text { 2. Determinação do } \\
\text { modo de governança e } \\
\text { de governabilidade } \\
\text { (DGG) }\end{array}$ & $\begin{array}{l}\text { Tensiona pela opção de governança mais ou menos democrática, bem como pelas } \\
\text { condições de capacidade institucional governamental e de funcionamento das } \\
\text { instituições executoras de políticas públicas, com implicações na legalidade e } \\
\text { legitimidade governamental. }\end{array}$ \\
\hline $\begin{array}{l}\text { 3. Determinação } \\
\text { institucional da polícia }\end{array}$ & $\begin{array}{l}\text { Tensiona com a qualidade do aparato e da atuação, bem como das condições } \\
\text { dialógicas com a população, apresentada pelas polícias e pela guarda municipal. (Uso } \\
\text { de equipamentos e métodos defasados e inapropriados, bem como pessoal com pouca } \\
\text { ou nenhuma qualificação produzindo ações ineficientes) }\end{array}$ \\
\hline
\end{tabular}




\begin{tabular}{|l|l|}
\hline $\begin{array}{l}\text { 4. Determinação } \\
\text { institucional da justiça } \\
\text { (DIJ) }\end{array}$ & $\begin{array}{l}\text { Tensiona com a qualidade do aparato e da atuação, bem como das condições } \\
\text { dialógicas com a população, apresentada pelos órgão e agentes da justiça. }\end{array}$ \\
\hline $\begin{array}{l}\text { 5. Determinação do } \\
\text { conhecimento } \\
\text { científico (DCC) }\end{array}$ & $\begin{array}{l}\text { Usos de metodologias ou técnicas baseadas em descobertas ou explicações científicas } \\
\text { expressas em tecnologias de processo, de organização ou de equipamentos relativos } \\
\text { à violência ou ao estabelecimento de cultura de paz. }\end{array}$ \\
\hline $\begin{array}{l}\text { 6. Determinação do } \\
\text { modo de ocupação } \\
\text { urbanística (DOU) }\end{array}$ & $\begin{array}{l}\text { Tensiona pela existência de contextos sócio-urbanos inseguros por serem ambientes } \\
\text { que oportunizam a presença de violência e de crime. }\end{array}$ \\
\hline $\begin{array}{l}\text { 7. Determinação de } \\
\text { atuação criminosa } \\
\text { (DAC) }\end{array}$ & $\begin{array}{l}\text { Tensiona pela existência de grupos organizados para prática da violência e pela prática } \\
\text { individual de crimes. }\end{array}$ \\
\hline $\begin{array}{l}\text { 8. Determinação de } \\
\text { Protagonismo (DPr) }\end{array}$ & $\begin{array}{l}\text { Tensiona pela manifestação de atuação da comunidade, } \\
\text { condução de processos e projetos coletivos. }\end{array}$ \\
\hline $\begin{array}{l}\text { Resiliência (DRs) } \\
\text { enfrentar e transformar as condições de vulnerabilidades pessoais ou sociais onde } \\
\text { estão inseridos. }\end{array}$ \\
na
\end{tabular}

Elaborado por Macêdo Filha, 2018 p. 59

O IQSC foi utilizado para validar as condições de segurança cidadã, a resistência e a resiliência da comunidade de Itinga. Este artigo irá utilizar a mesma abordagem, a partir da Hemeroteca produzida por Macêdo Filha (2018) em sua tese, mediante pesquisa com a palavra chave - Oasis. O objetivo desta busca é identificar através de análise da metodologia aplicada, qual impacto o jogo oásis aplicado pela Unesco na comunidade de Itinga - Lauro de Freitas, contribuiu para as condições de protagonismo e segurança cidadã na comunidade. Antes de mergulhar na análise das evidências coletadas na hemeroteca, faz-se necessário entender o que é o jogo Oasis, tecnologia social de transformação comunitária.

\subsection{Tecnologia social jogo Oasis}

Segundo o Instituto de Tecnologia Social - Brasil, tecnologias sociais são "conjunto de técnicas e metodologias transformadoras, desenvolvidas e/ou aplicadas na interação com a população e apropriadas por ela, que representam soluções para inclusão social e melhoria das condições de vida" (ITS BRASIL, 26). 
Um dos seus principais objetivos é a promoção do desenvolvimento sustentável a partir da promoção do protagonismo social, cuidado ao meio ambiente, economia solidária, educação e respeito às manifestações culturais.

Para Aldalice Moura da Cruz Otterloo (2010), as tecnologias sociais apresentam efetivas soluções para a transformação social. Ela acrescenta que:

faz-se necessário ampliar e fortalecer os processos em curso que disseminam o conceito de tecnologia social e constroem espaços coletivos que agregam diferentes atores sociais, para que se reconheçam como produtores de uma nova cultura política de participação e formas inovadoras de produção e de consumo; e intensificar as ações de comunicação sobre a identidade e a atuação das organizações e movimentos comunitários e prosseguir o debate da inter-relação Estado e sociedade civil no que se refere à autonomia e à participação qualificada na construção da esfera pública. (OTERLOO, 2010 p. 17)

Diante do que Ortello (2010) apresenta, podemos compreender que as tecnologias sociais não são apenas elementos de transformação política, e econômica, mas também uma forma de estreitar relações entre os indivíduos que estão inseridos na realidade onde é aplicada. As tecnologias sociais podem ser divididas em: (i) Produtos, dispositivos ou equipamentos; (ii) Processos, procedimentos, técnicas ou metodologias, serviços, inovações sociais organizacionais; (iii) inovações sociais de gestão.

O jogo Oasis é uma ferramenta de apoio à mobilização cidadã para realização de sonhos coletivos, criado pelo Instituto Elos. A metodologia desenvolvida pelo Instituto para o Jogo Oasis busca promover a relação das pessoas em três níveis diferentes: a pessoa (i) consigo mesma; (ii) com a comunidade; e (iii) com o mundo.

Composto por jogadores e comunidade, o jogo considera uma definição ampla de comunidade que envolve diversos atores, como moradores, ONGs, governo local, lideranças e empresas. Concebido para ser de uso livre e praticado de forma totalmente cooperativa, para que todos, juntos, realizem algo em comum, o Oasis propõe regras que permitem a vitória de todos, sem exceção. (JOGO OASIS, 2019).

A comunidade tem uma experiência prática de uma vivência em transformação social e inclusão social, que ajuda estreitar os laços comunitários a fim de estimular o seu protagonismo. As imagens a seguir ilustram como é o jogo: 
Figura 1: Elementos que compõem o jogo Oasis

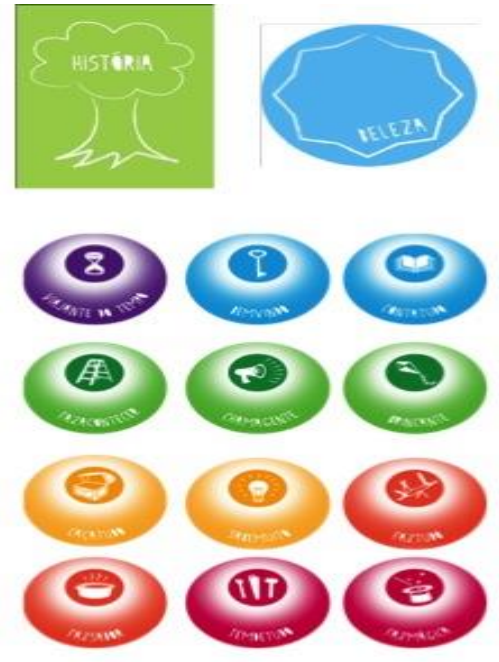

CRACHÁS DOS PERSONAGENS
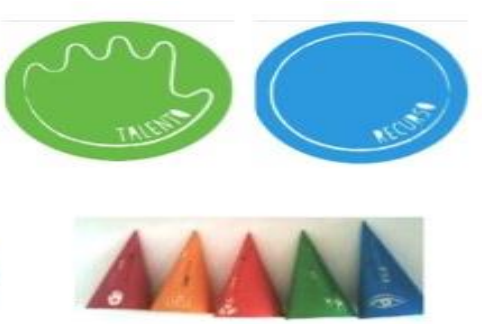

TOTENS
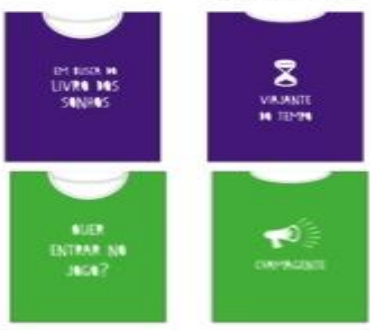

COLETES DOS PERSONAGENS

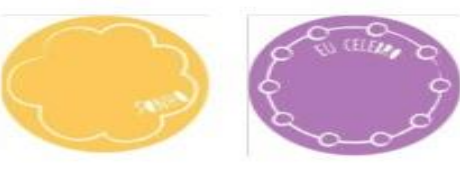

MARCADORES

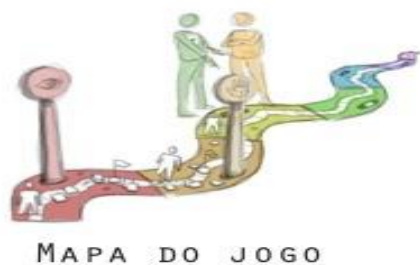

MAPA DO JOGO

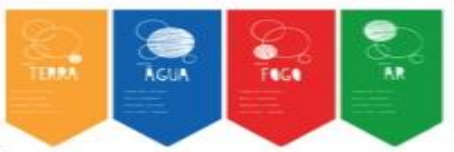

BANDEIRAS DO T I MES

Fonte: Instituto Elos

Figura 2: Os sete passos do jogo oasis

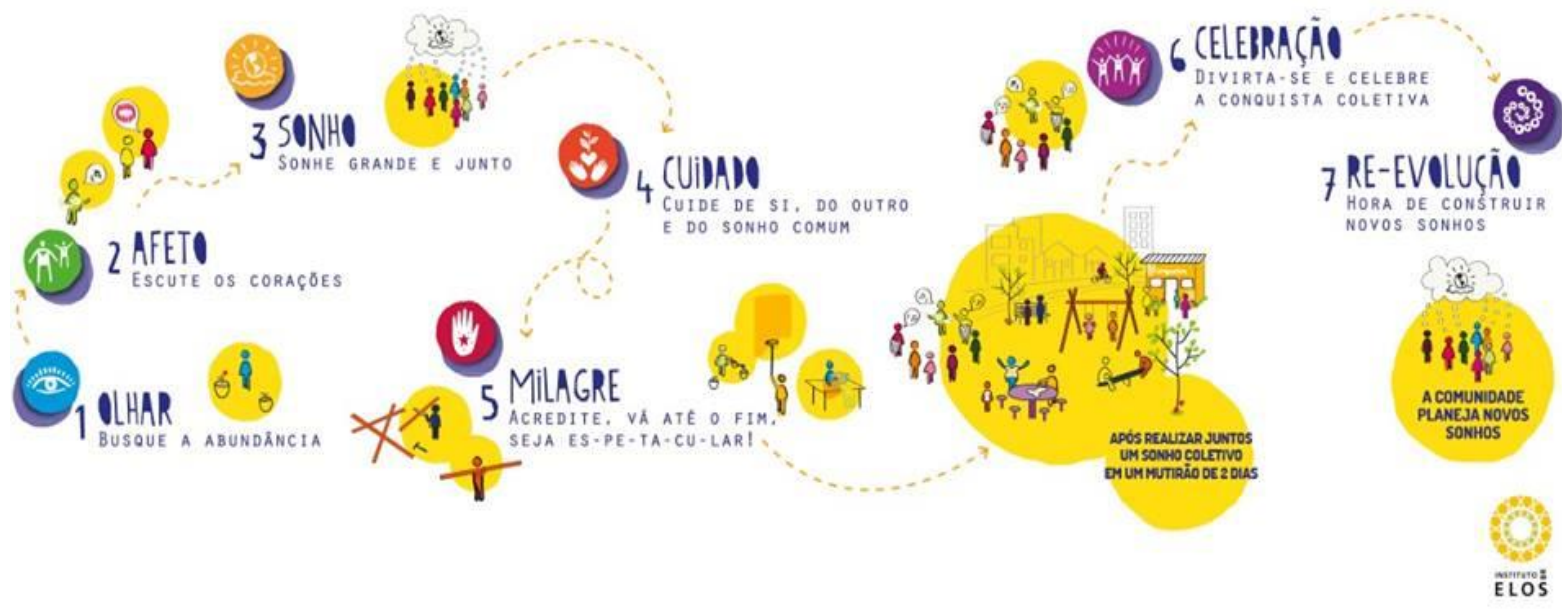

Fonte: Instituto Elos

Os sete (7) passos do jogo é organizado da seguinte forma:

- Olhar: Cultivo da visão apreciativa sobre o grupo e ambiente, criando um cenário abundante em belezas (naturais e artificiais, sensoriais, pequenos gestos etc). Trata-se de valorizar o potencial que cada pessoa tem em contribuir. Conhecer a comunidade e identificar a presença de recursos materiais locais e construídos.

- Afeto: O processo compreende a busca pela "pessoa por trás da beleza", por meio de passeio e conversas pela comunidade, com objetivo de estimular o estabelecimento de relações entre as pessoas e confiança, de forma a fortalecer o trabalho coletivo. Nesta etapa são descobertas histórias e talentos na comunidade, por meio da "escuta ativa" (conceito trabalhado no Jogo e em outras ferramentas de 
desenvolvimento pessoal e de grupos). As descobertas são sistematizadas em modelos de mapas mentais previamente impressos;

- Sonho: consiste em criar condições (espaço e relação) para que as aspirações coletivas que todos temos possam ser expressas. É necessário ir além da prática comum de identificar problemas. Para tanto, é construída uma árvore dos sonhos, na qual são incluídas as aspirações dos integrantes do grupo que passa pela capacitação, e de pessoas com as quais cada participante do Jogo possa conversar;

- Cuidado: estabelecimento cuidadoso de estratégias e projetos que contemplem as expectativas de um conjunto de sonhos e de pessoas envolvidas. Caminhando juntos, cuidando de si, do outro e do sonho comum. É marcada uma reunião denominada "Encontro dos Sonhos", na qual participam tanto o grupo que passa pela formação quanto a comunidade que está sendo mobilizada. Nesta reunião chega-se a um sonho coletivo, para o que estimula-se o grupo a pensar em sonhos materializáveis em dois dias de mutirão (começo-meio-fim). O sonho coletivo é representado materialmente via construção conjunta de uma (ou várias) maquete(s). Nesta etapa também são divididas equipes (Grupo recepção, grupo mural, grupo geração de renda etc) e são captados recursos locais. Contatos podem ser feitos para recolhimento de possíveis doações. O material disponível para a ação (mão na massa) é apenas aquele que o grupo conseguir captar;

- Milagre: momento de fazer o "impossível acontecer", tendo como base a união do grupo e os materiais que foram reunidos;

- Celebração: reencontro para partilhar a alegria da realização conjunta, reconhecendo e comemorando a contribuição de cada um para a conquista coletiva. Nesta etapa a realização materializada e a experiência vivida ganham ainda mais sentido. Realização de cortejo aos locais do Milagre. Roda de compartilhamento das experiências vividas. Apresentação das fotos. É estimulada a celebração com talentos locais;

- Re-evolução: impulso para um novo ciclo de realizações, a partir da formação de uma rede de parceiros e de sonhos coletivos em movimento de expansão. Momento de planejar ações a partir da iniciativa e autonomia conquistadas pela comunidade ("Se tudo fosse possível, que futuro você desejaria?"). Nesta etapa é realizada uma nova reunião: o "Encontro de Futuro" com a comunidade e rede de parceiros. Convidar a comunidade a visitar projetos bem sucedidos e relacionados aos sonhos do futuro. Lançar um novo desafio. Exemplos de ferramentas a serem utilizadas: Open Space e World Café.

Em Itinga, o jogo foi apresentado como a tecnologia social aplicada pela UNESCO em parceria com o Instituto Elos dentro das ações do eixo IFortalecimento da Coesão Social do Programa Conjunto da ONU- Segurança com Cidadania, na comunidade do Jardim Talismã- Itinga- Lauro de Freitas, na região metropolitana de Salvador-BA, de maio a junho de 2013, reunindo cerca de 421 pessoas; 26 foram formados na metodologia e compuseram o grupo de mobilizadores sociais, 9 servidores públicos de diferentes setores do governo 
municipal e 6 líderes comunitários locais (PNUD, 2013 p. 65). E na etapa milagre foi feita a revitalização da sede da Associação dos Moradores com a criação de uma área de lazer e um parquinho para as crianças.

\subsection{Análise das evidências- Jogo Oasis como ferramenta de transformação social em Itinga}

Na pesquisa feita na hemeroteca produzida por Macêdo Filha (2018) na sua tese, utilizando a palavra-chave Oasis foi possível identificar 5 evidências. Uma na revista Villa Magazine, periódico local da cidade de Lauro de Freitas e as outras quatro nas tabelas de determinações e variáveis feitas com as entrevistas e relatos de moradores, lideranças comunitárias e alguns servidores públicos durante a avaliação do programa conjunto da ONU. Nas cinco evidências apresentadas é possível localizar as tensões por resiliência, por participação e por vulnerabilidade. A determinação por protagonismo (DPr) aparece em todas as evidências, assim como as determinações por ocupação do espaço (DOU), determinação por governança e governabilidade (DGG), determinação sociointeracional (DSI) e determinação por resiliência (DRs).

Os diagramas a seguir foram feitos baseados na representação feita por Macêdo Filha (2018) e demonstram como se organizam as interseções das evidências, tensões e determinações.

Figura 3. Diagrama 1 de interseções entre evidências, tensões e determinações - T1, T2, T3 - Villa Magazine - 2013. Edição 174.

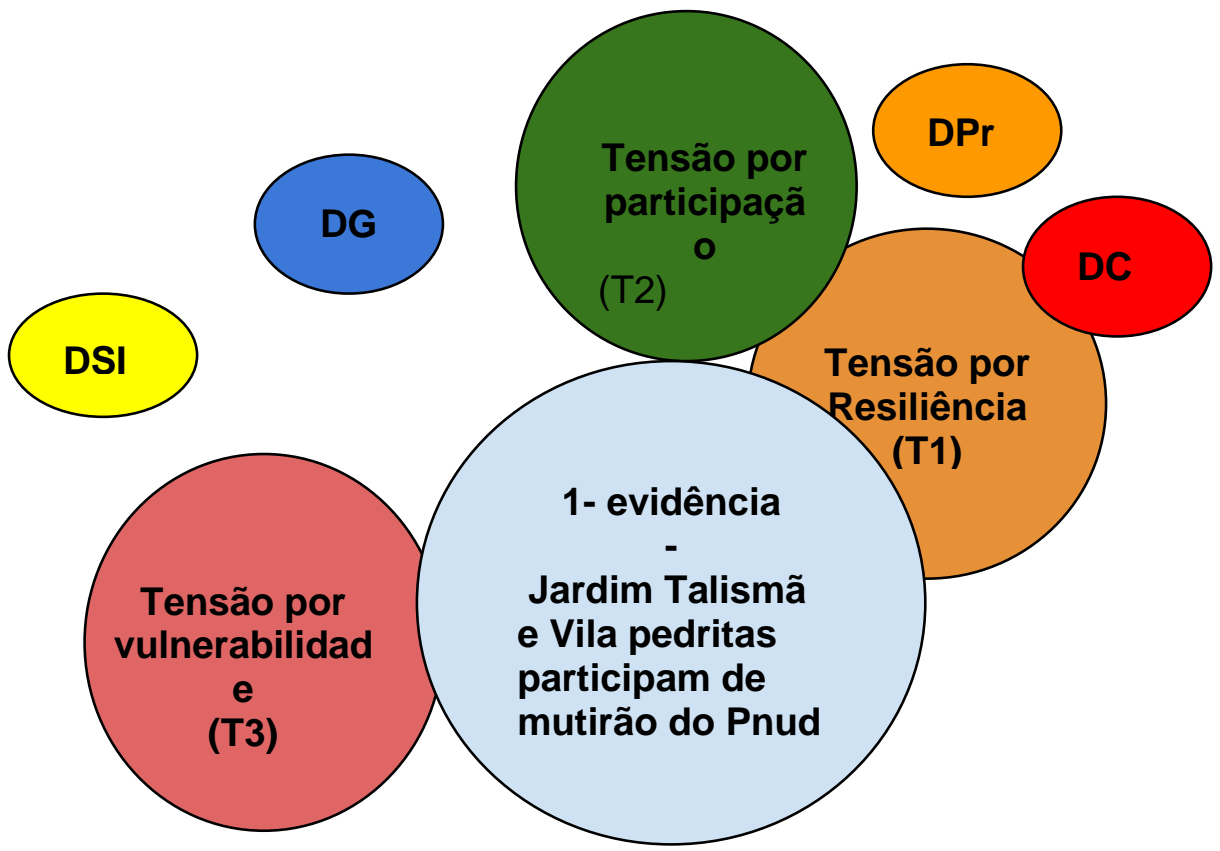

Elaborado pela autora com base ao diagrama de Macêdo Filha, 2018 p. 109

A primeira evidência foi retirada da reportagem: "Jardim Talismã e Vila Pedrita participam de mutirão do PNUD" da revista Villa Magazine,edição: 174, pág. (p.24) . Localizada no quadro 181- Variáveis e determinações, revista Villas Magazine, Itinga, 2013. (MACÊDO FILHA, 2018 p. 305- 307). 
Moradores de Itinga realizaram em junho um mutirão de reforma da sede da Associação de Moradores do Jardim Talismã para transformar o espaço em área cultural, de lazer e de mobilização comunitária. Voluntários foram convidados a participar com mão de obra e doação de materiais. Construir um sonho comum, cada um contribuindo com uma pequena parte para melhorar o coletivo foi o objetivo do mutirão. A comunidade mobilizou-se para conseguir materiais, alimentos e mão de obra para reforma e melhoria da sede da associação de moradores. Com a reforma finalizada, este será o primeiro espaço de lazer e cultura da comunidade. A atividade é parte do Jogo Oásis, uma capacitação que está sendo desenvolvida pela UNESCO, em parceria com o Instituto Elos, dentro do Programa Conjunto da ONU "Segurança com Cidadania". O Jogo é uma ferramenta de apoio à mobilização cidadã e à realização de sonhos coletivos, a partir de um desafio rápido para a transformação física de uma realidade. A primeira etapa da atividade aconteceu em maio e contou com a participação de cerca de 50 pessoas. Nessa primeira oficina, os participantes foram desafiados a encontrar talentos na comunidade artesãos, marceneiros, cozinheiros, entre outros. Em seguida, eles foram incentivados apensar juntos num sonho comum, que pudesse ser realizado de forma prática. Assim, em conjunto, a comunidade construiu três maquetes. Uma delas, a que projeta a reforma da associação, foi eleita pela comunidade para ser executada.O grupo de voluntários teve dois dias para realizar as ações previstas. Entre elas, a criação de um parquinho para as crianças, uma área de lazer e jogos, a reforma dos banheiros da associação, a criação de mobiliário para um espaço sociocultural, a limpeza da área do entorno do córrego que passa em frente à associação para criação de uma área de convivência com bancos, jardins e floreiras. Três grupos atuaram na mobilização para conseguir materiais de construção, tinta, cimento, lajota, madeira, pincéis e também alimentos, já que as refeições dos dois dias de trabalho foram preparadas de forma coletiva.(...) Não existem postos de saúde, nem escolas instaladas no local. O Jogo Oásis é uma ação da Organização das Nações Unidas para Educação, Ciência e Cultura (Unesco), dentro do Programa Conjunto da ONU "Segurança com Cidadania: prevenindo a violência e fortalecendo a cidadania com foco em crianças, adolescentes e jovens em condições vulneráveis em comunidades brasileiras", que está sendo desenvolvido em Lauro de Freitas, Contagem (MG) e Vitória (ES)(..). (VILAS MAGAZINE, 2013 p. 24 apud MACÊDO FILHA, 2018 p. 305-307)

A reportagem fala sobre a aplicação da metodologia de mobilização comunitária- Jogo Oasis na comunidade pela Unesco em parceria com o Instituto Elos em 2013 como parte das ações do programa conjunto da ONU. Nota-se no diagrama apresentado acima, que essa evidência está diretamente interligada às tensões por participação e protagonismo (T2), por vulnerabilidade (T3) e por resiliência (T1). A tensão por Criminalidade (T4) não aparece. A determinação sociointeracional (DSI) apresenta que a comunidade não tem acesso a informação, além de não ter posto de saúde e escola como variáveis. Tais variáveis dialogam diretamente com a determinação por governança e governabilidade (DGG) que através do programa conjunto da ONU promove uma ação intergovernamental. As tensões 1 e 2 estão interligadas pois com a aplicação da metodologia de 
mobilização comunitária e transformação social - jogo Oasis foi possível identificar a participação da comunidade e das lideranças locais empenhadas na realização de um sonho comum- que era transformar associação dos moradores na primeira área de lazer e cultura da comunidade.

As outras quatro evidências foram agrupadas num mesmo diagrama, pois todas apresentaram semelhantemente as mesmas determinações e tensões. Vale ressaltar que só foram utilizadas para diagramação das interseções os quadrantes que expressavam diretamente o Jogo- Oasis, metodologia pela qual estamos analisando aqui.

Figura 4. Diagrama 2 de interseções entre evidências, tensões e determinações - T1, T2, T3 - Nas entrevistas com lideranças, servidores públicos e representação juvenil- p. 495 a 505

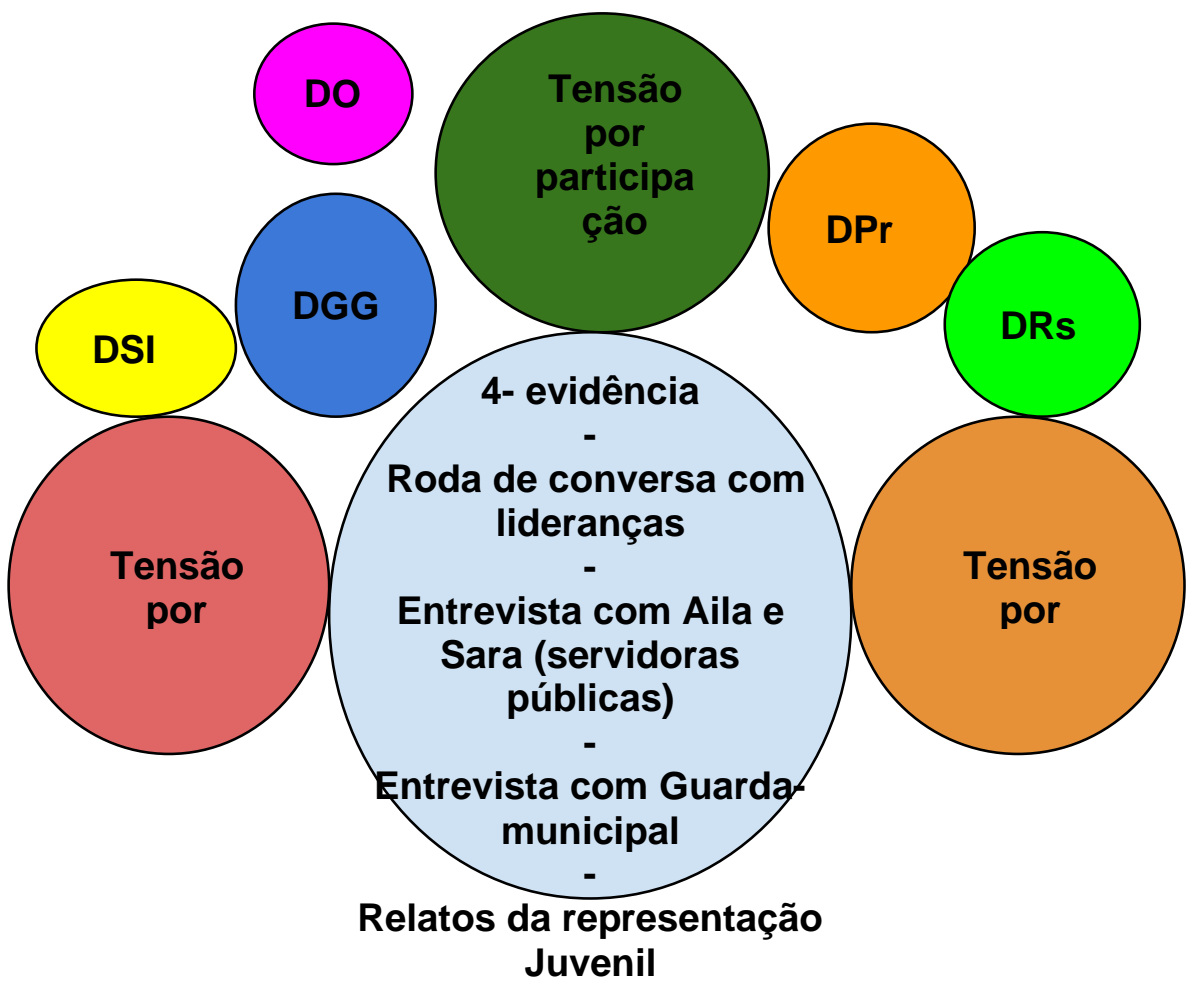

Elaborado pela autora com base ao diagrama de Macêdo Filha, 2018 p. 109

Nas quatro evidências apresentadas, as tensões por resiliência (T1), por participação (T2) e por vulnerabilidade (T3) aparecem e são explicadas pelas as mesmas determinações. As entrevistas que constam na hemeroteca foram feitas durante a fase de avaliação do programa conjunto. As narrativas expressam os impactos da aplicação da metodologia na comunidade. As determinações por governança e governabilidade (DGG) e sociointeracional (DSI) dialogam com as variáveis apresentadas em que houve falha na continuidade do projeto e interferência dos órgãos públicos etc. A determinação pelo uso do espaço (DOU) aparece por conta da modificação do espaço pela comunidade. Em contraponto as tensões por participação (T2) e por Resiliência (T1) geram determinações por resiliência (DRs) e por protagonismo (DPr) e apresentam através das suas variáveis que aplicação do jogo gerou um novo olhar sobre a comunidade, realização de um sonho conjunto, envolvimento das lideranças locais e poder público e jovens como 
agentes de transformação da sua comunidade etcs. Um dos líderes comunitários apresenta a seguinte fala na entrevista com as lideranças locais:

(...)um trabalho que eu já fazia com os meninos lá na rua e eu ganhei mais experiência, desde quando chegou, orientou, capacitou a gente para desenvolver o projeto, demonstrando a gente como desenvolver e a participação dentro do programa foi bom porque a gente não tinha padrão, a gente não tinha material esportivo, então a ajuda do programa foi melhor que desenvolver o projeto. A gente já saiu para outros bairros, se comunicou com as pessoas, fomos jogar fora, fomos jogar no centro de Lauro, a gente foi jogar, Josenilson com aquele carrinho dele lá ajudou muito, era eu e Josenilson, a gente se picar por aí e a mãe reclamando "O carro está cheio demais para esses meninos", mas não tinha outro objetivo, né? (...)Eu sei que eu estou salvando vidas, então foi gratificante, muito importante esse projeto ter ido lá para o nosso bairro, eu espero que através de vocês de novo dê mais uma força lá para a gente fortalecer mais.(...) MACÊDO FILHA, 2018 p. 496 )

O relato coletado aponta que a aplicação da metodologia e o projeto travessia cidadã (projeto de mobilização e articulação comunitária que foi para a comunidade durante o programa conjunto da Onu) foi de extrema importância para que suas habilidades quanto agente de transformação social fossem potencializadas.

\section{CONSIDERAÇÕES FINAIS}

Os indícios de que a aplicação do jogo contribuiu diretamente para as condições de protagonismo e segurança cidadã da comunidade são identificadas não apenas com a aplicação do IQSC que valida nosso questionamentos, mas também ao ler as narrativas apresentadas na hemeroteca. Macêdo Filha (2018) nos apresenta que o protagonismo que qualifica a resiliência na construção da territorialidade cidadã em Itinga, protagonismo comunitário de enfrentamento ao medo na perspectiva da segurança cidadã possibilita tornar visível o potencial de enfrentamento ao medo da comunidade (MACÊDO FILHA, 2018 p. 124).

Itinga, que vista pelo olhar de quem está de fora como uma comunidade violenta, é tida como um lugar de resistência e protagonismo por quem mora e vive dentro dela. Esse olhar de resistência e protagonismo por dentro, pela população que vive o cotidiano de ambiente classificado como socialmente vulnerável pelos de fora, nos instiga a continuar a imersão junto à comunidade Mané Dendê que, comparativamente, se encontra lutando por sua identidade frente ao que se anuncia como Novo Mané Dendê, intervenção da Prefeitura do Município, conforme o olhar dos de fora.

\section{AGRADECIMENTOS}

Agradeço a Joselita Frutuoso de Araújo Macêdo Filha (in memoriam) pela sensibilidade da pesquisa em Itinga, pelas orientações e por ter me apresentado ao grupo de pesquisa Desenvolvimento, Sociedade e Natureza- DSN/UCSAL, ao qual eu sou grata pelo acolhimento e incentivo a pesquisa, em especial a Débora 
Porciúncula e a Profa. Dra. Cristina Maria Macêdo de Alencar pela orientação. Ao Instituto Elos, pela bolsa concedida para fazer o curso Guerreiros Sem Armas-2019 e me possibilitar aprofundamento no estudo da Filosofia Elos e jogo Oasis. 


\title{
Building safe communities: Oasis game and the conditions of protagonism and citizen security of the community of Itinga- Lauro de Freitas
}

\begin{abstract}
This article presents how the social mobilization and community transformation game created by Instituto Elos, an oasis game, contributed to the conditions of citizen security in the community of Itinga-Lauro de Freitas, in 2013 during the actions of the Joint Program of the UN - Security with Citizenship. To verify the conditions of citizen security, mobilization and community role within the community, the Qualitative Indicator of Citizen Security - IQSC, produced by Joselita Frutuoso Macêdo Filha in his doctoral thesis by the Postgraduate Program in Territorial Planning and Social Development, was used of the Catholic University of Salvador- (PPGPTDS / UCSAL). In order to collect the evidence, a research was carried out in the press library produced by it, using the keyword: Oasis and the results were analyzed and organized in this article.
\end{abstract}

KEY WORDS: Itinga. Play Oasis. Citizen Security. IQSC. 


\section{REFERÊNCIAS}

ALENCAR, CRISTINA MARIA MACÊDO; FLEXOR, MARIA HELENA OCHI. Estado, políticas públicas e capitalismo: múltiplas interpretações In A Cidade Urbanometropolitana de Lauro de Freitas . Campinas/SP: Átomo \& Alínea, 2012, p. 181206,

Cartilha do plano Integral e Participativo em Convivência e Segurança Cidadã de Itinga, Lauro de Freitas, Bahia. Brasília: PNUD, 2013.

DIAS, PATRÍCIA CHAME. Da periferia distante à periferia próxima: notas sobre a construção de um bairro popular na Região Metropolitana de Salvador. Disponível em <file:///C:/Users/maris/Downloads/3039-7203-1-PB.pdf> Acesso em 30 dez 2019.

IITS BRASIL. O que são tecnologias sociais. Disponivel em <http://itsbrasil.org.br/conheca/tecnologia-social/> Acesso 02 Dez 2018.

INSTITUTO ELOS. O que é o jogo oasis?. Disponível em <https://www.youtube.com/watch?v=UnB9y_c8pdE> Acesso em 18 out 2019

HERCOG, Bruna Pegna. De "menino" a "elemento": onde trajetórias se cruzam. Um estudo sobre juventudes e violências com adolescentes jovens e policiais militares em Itinga, Lauro de Freitas-BA. Salvador, 2016. Disponível em <https://repositorio.ufba.br/ri/bitstream/ri/27469/1/Disserta\%C3\%A7\%C3\%A3o \%20BRUNA\%20HERCOG_vers\%C3\%A30\%20para\%20depositar.pdf> Acesso em 20 dez 2019.

Jogo oasis. Disponivel em <http://www.institutoelos.org/games/games/view/jogo-oasis> Acesso em 17 out 2019

MACÊDO FILHA, JOSELITA FRUTUOSO DE ARAÚJO. A ira fértil: resiliência na resistência ao medo em Itinga - Lauro de Freitas. Salvador, 2018. 520 f. Disponível em <https://drive.google.com/open?id=0B3_Ax5aSTz_SZVRIQjlHdUNfNIhMN2IwQkZ YZUhpNUt4S2t3> acesso 16 out 2019.

ONODC. Prevenção ao Crime e Justiça Criminal: ações. Disponivel em <https://www.unodc.org/lpo-brazil/pt/crime/mdgf--programa-conjuntoonu.html> Acesso em 18 dez 2019. como política pública. Disponivel em< http://www.mobilizadores.org.br/wp- 
content/uploads/2014/05/4-social-tecnologia-social-e-desen-sustentavel.pdf> Acesso 17 out 2019.

PNUD. Caderno Municipal do Programa Conjunto da ONU Segurança com Cidadania - prevenindo a violência e fortalecendo a cidadania com foco em crianças, adolescentes e jovens em condições vulneráveis em comunidades brasileiras. Brasília: PNUD, 2013

SEBRAE. Tecnologias sociais : Como os negócios podem transformar comunidade. Disponivel em <http://sustentabilidade.sebrae.com.br/Sustentabilidade/Para\%20sua\%20empre sa/Publica\%C3\%A7\%C3\%B5es/Tecnologias-Sociais-final.pdf> Acesso em 17 out 2019

Recebido: 13 jul. 2020.

Aprovado: 23 ago. 2020.

DOI: $10.3895 /$ rbpd.v9n4.13003

Como citar: FONSECA, M. S. Construindo comunidades seguras: jogo Oasis e as condições de

protagonismos e segurança cidadã da comunidade de Itinga - Lauro de Freitas. R. bras. Planej. Desenv.

Curitiba, v. 9, n. 4, p. 565-582, Edição Especial V Seminário Nacional de Planejamento e Desenvolvimento,

out. 2020. Disponível em: <https://periodicos.utfpr.edu.br/rbpd>. Acesso em: XXX.

Correspondência:

Mirian Souza Fonseca

Av. Adhemar de Barros, s/no - Ondina, Salvador - BA

Direito autoral: Este artigo está licenciado sob os termos da Licença CreativeCommons-Atribuição 4.0

Internacional.

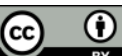

